\title{
Relating Peanut Rx Risk Factors to Epidemics of Early and Late Leaf Spot of Peanut
}

\author{
Abraham M. Fulmer, ${ }^{1}$ Lucky K. Mehra, ${ }^{2}$ Robert C. Kemerait Jr., ${ }^{1, \dagger}$ Timothy B. Brenneman, ${ }^{1}$ Albert K. Culbreath, ${ }^{1}$ \\ Katherine L. Stevenson, ${ }^{1}$ and Emily G. Cantonwine ${ }^{3}$ \\ ${ }^{1}$ Department of Plant Pathology, The University of Georgia, Tifton, GA 31793 \\ 2 Department of Plant Pathology, Kansas State University, Manhattan, KS 66506 \\ ${ }^{3}$ Department of Biology, Valdosta State University, Valdosta, GA 31698
}

\begin{abstract}
Previous research has demonstrated the efficacy of prescription fungicide programs, based upon Peanut Rx, to reduce combined effects of early leaf spot (ELS), caused by Passalora arachidicola (Cercospora arachidicola), and late leaf spot (LLS), caused by Nothopassalora personata (syn. Cercosporidium personatum), but the potential of Peanut Rx to predict each disease has never been formally evaluated. From 2010 to 2016, non-fungicide-treated peanut plots in Georgia and Florida were sampled to monitor the development of ELS and LLS. This resulted in 168 cases (unique combinations of Peanut Rx risk factors) with associated total leaf spot risk points ranging from 40 to 100 . Defoliation ranged from 13.9 to $100 \%$, and increased significantly with increasing total risk points (conditional $\mathrm{R}^{2}=0.56 ; P<0.001$ ). Leaf spot onset (time in days after planting [DAP] when either leaf spot reached $1 \%$ lesion incidence), ELS onset, and LLS onset ranged from 29 to 140, 29 to 142, and 50 to 143 DAP, respectively, and decreased significantly with increasing risk points. Standardized AUDPC of ELS was significantly affected by risk points (conditional $\mathrm{R}^{2}=0.53, P<0.001$ ), but not for LLS. After removing redundant Peanut Rx factors, planting date, rotation, historical leaf spot prevalence, cultivar, and field history were used as fixed effects in mixed

effect regression models to evaluate their contribution to leaf spot, ELS or LLS prediction. Results from mixed effects regression confirmed that the selected Peanut Rx risk factors contributed to the variability of at least one measurement of development of combined or separate epidemics of ELS and LLS, but not all factors affected ELS and LLS equally. Historical leaf spot prevalence, a new potential preplant risk factor, was a consistent predictor of the dominant disease(s) observed in the field. Results presented here demonstrate that Peanut Rx is a very effective tool for predicting leaf spot onset regardless of which leaf spot is predominant, but also suggest that associated risk does not reflect the same development for each disease. These data will be useful for refining thresholds for differentiating high, moderate, and low risk fields, and reevaluating the timing of fungicide applications in reduced input programs with respect to disease onset.

Keywords: Peanut Rx, Cercospora arachidicola, Passalora arachidicola, early leaf spot, Cercosporidium personatum, Nothopassalora personata, late leaf spot, groundnut, fungi, field crops, oilseeds and legumes, disease management, epidemiology, disease warning systems
\end{abstract}

Prophylactic application of fungicide is a primary tactic for managing early leaf spot (ELS) of peanut (Arachis hypogaea L.) caused by Passalora arachidicola (Hori) U. Braun (syn. Cercospora arachidicola Hori) and late leaf spot (LLS) caused by Nothopassalora personata (Berk. \& M.A. Curtis) U. Braun, C. Nakash., Videira \& Crous (syn. Cercosporidium personatum (Berk \& M.A. Curtis) Deighton), (Shokes and Culbreath 1997; Videira et al. 2017). Historically, fungicides have been applied on a calendar-based schedule, beginning just before or at the expected time of disease onset (30 days after planting [DAP]), and subsequently sprayed every 14 days until 2 to 3 weeks prior to harvest ( 140 DAP) (Culbreath et al. 2006). These fungicide applications represent one of the highest input costs for peanut growers in Georgia, where the annual average damage plus cost of control from 2013 to 2015 was estimated at $\$ 35.2$ million (Kemerait 2013, 2014, 2015). As a result, a number of strategies have been investigated to reduce the number of applications. Weatherbased advisories have been a major focus over the last 50 years (Damicone et al. 1994; Davis et al. 1993; Jensen and Boyle 1966; Parvin et al. 1974; Phipps and Powell 1984) and have been particularly successful in North Carolina, Oklahoma, and Virginia (Damicone et al. 1994; Phipps et al. 1997). The AU-Pnuts weather advisory (Jacobi et al. 1995) is recommended in Georgia (Kemerait

${ }^{\dagger}$ Corresponding author: R. C. Kemerait Jr.; kemerait@uga.edu

The author(s) declare no conflict of interest.

Accepted for publication 18 June 2019.

(C) 2019 The American Phytopathological Society et al. 2017), but has not been widely adopted by growers (Woodward et al. 2008).

A more recent alternative for reducing fungicide inputs is to use prescription program based on Peanut Rx (a disease risk index), for the most important foliar and soilborne diseases of peanut (Kemerait et al. 2004; Woodward 2006). Peanut Rx was developed after factors included in the widely adopted Tomato Spotted Wilt Virus Risk Index were found to also influence the severity of other diseases (Kemerait et al. 2004). Peanut Rx considers ELS and LLS together, as a leaf spot complex, and assigns risk based on cultivar planted, planting date, crop rotation, field history of disease, and irrigation (Kemerait et al. 2017). Risk points are assigned to each factor, and the total points are used to classify a field as a high, moderate, or low risk for disease. High-risk fields are treated according to the standard 7-spray, 14-day calendar based program (initiated at 30 DAP), but are reduced to five applications in moderate-risk fields (initiated at 37 DAP with 14- and 21-day intervals) and four applications in low risk fields (initiated at 44 DAP with 21-day intervals) (Kemerait et al. 2017).

While the efficacy of prescription fungicide programs based on Peanut Rx has been tested in fields with varying risk levels (Woodward et al. 2010, 2014), the effect of risk points on disease development has not been formally assessed. It is also not known if ELS and LLS disease are equally well predicted by Peanut Rx, since the index currently assigns risk to these diseases together.

ELS and LLS are similar in many respects, but there are several key differences in their epidemiology that may affect prediction of one or both diseases. The most characteristic difference, as indicated by their names, is time of disease onset. When inoculum of both pathogens are present in a field, the onset of ELS typically occurs 30 to 50 DAP in the southeastern United States and 2 to 4 weeks earlier than LLS (Shokes and Culbreath 1997; Smith and Littrell 1980). Another 
important difference is that LLS typically has a faster rate of development toward the end of the season due to a greater amount of sporulation per lesion (Backman and Crawford 1984; Hemingway 1955; Jenkins 1938).

The usefulness of Peanut Rx at predicting epidemic development of these diseases may be further challenged, because the prevalence of ELS and LLS differs across fields. Although capable of coexisting in the same field and even on the same leaflet, the relative abundance of each disease tends to vary over time both regionally (Miller 1953) and locally (Jackson 1981). In the late 1930s, Jenkins stated that LLS only occurred two out of every five years in Georgia, and Miller (1953) reported that ELS was the more widespread of the two diseases in the southeastern United States. In Georgia, ELS was the most prevalent disease until a shift took place in 1976, and LLS prevailed until the mid-1990s (Cantonwine et al. 2008; Smith and Littrell 1980). In recent years, there has been a resurgence of LLS in Georgia, and it is possible to have nearby fields that are historically ELS or LLS (Fulmer 2017).

There is a very practical need to evaluate the efficacy of Peanut Rx to predict the risk of ELS and LLS in fields with one or both diseases. Therefore, the objectives of this study were to 1) determine the effect of Peanut Rx risk points on ELS epidemics, LLS epidemics, and combined ELS and LLS epidemics; 2) evaluate the contribution of each Peanut Rx factor in the development of ELS epidemics, LLS epidemics, and combined epidemics of ELS and LLS; and 3) determine if historical leaf spot prevalence has the potential to predict the dominating leaf spot in the following growing season.

\section{Materials and Methods}

Field sites and data source. Data were obtained from nonfungicide-treated peanut plots from a wide range of studies with differing treatment protocols at multiple research sites during the 2010 to 2016 growing seasons (Tables 1 and 2). All data came from plots with plants that were infected by naturally occurring inoculum of the LLS and ELS pathogens. Herbicides, insecticides, and fertilizers were applied following recommendations of the University of Georgia Cooperative Extension Service (Beasley 2010). Experimental designs included randomized complete blocks and split plots with three to five replicates. All plots consisted of two single rows spaced $91 \mathrm{~cm}$ apart and planted at 19.2 seeds $/ \mathrm{m}$. Plot lengths ranged from 4.6 to $12.2 \mathrm{~m}$.

Risk factors and associated risk points. For each field case, risk points were assigned using Peanut Rx based on cultivar planted, planting date, crop rotation, tillage, irrigation, and field (disease) history (as described below; Kemerait et al. 2017; Table 3). A histogram was plotted to show the frequency distribution of risk points. Cultivars were assigned risk points following the Peanut Rx values. Those cultivars not included in Peanut Rx were assigned points based on the combined knowledge and experience of the authors. Tillage systems were implemented as described by Monfort et al. (2004). Overhead irrigation was applied according to moisture recommendations from the University of Georgia Cooperative Extension Service (Beasley 2010). Field history was designated as 'Yes' to fields that had a high probability of harboring inoculum of one or both of the leaf spot pathogens, e.g., fields that had previously been used for fungicide studies that included nontreated plots, and 'No' to fields with a rotation $>3$

Table 1. Number of cases (unique combinations of Peanut Rx risk factors) in Georgia and Florida for each year

\begin{tabular}{lc}
\hline Year & Frequency \\
\hline 2010 & 5 \\
2011 & 11 \\
2012 & 12 \\
2013 & 8 \\
2014 & 39 \\
2015 & 46 \\
2016 & 47 \\
Total & 168 \\
\hline
\end{tabular}

years, or for fields where diseases were heavily managed with fungicides in the previous seasons.

Historical leaf spot prevalence. Fields were assigned to one of the following four categories based on previous records of leaf spot prevalence: ELS, LLS, both, or unknown. ELS and LLS signifies that fields had previously been documented to have a history of being predominantly ELS or LLS, respectively. 'Both' signifies that both diseases were known to contribute to the overall leaf spot epidemic in the previous peanut cropping season. 'Unknown' signifies that there was no record or knowledge of which disease was prevalent and was generally associated with fields that had been out of peanut for $>5$ years. Because historical leaf spot prevalence is not currently listed as a risk factor in Peanut Rx, no risk points were associated with this variable. Rather, these data were assembled to determine if historical leaf spot prevalence could help explain the variability in the onset and development of early and late leaf spot.

Disease assessment. Beginning approximately 30 DAP, five arbitrarily selected $1 \mathrm{~m}$ row sections of peanuts per plot were visually inspected for initial leaf spot symptoms. Upon first detection of leaf spot symptoms (or at 45 DAP even where no leaf spot symptoms had been found), a more intensive evaluation was initiated and continued approximately on a biweekly schedule until the end of the peanut season ( 140 DAP). Five main stems per plot were arbitrarily selected and excised at the base of the plant with handheld pruners. Samples were then bagged and returned to the lab where the number of missing leaflets, and the number of ELS and LLS lesions per remaining leaflet, were counted. ELS and LLS were differentiated by symptoms and signs associated with each pathogen that causes these diseases.

Time of disease onset was defined as the number of DAP for ELS or LLS to reach $1 \%$ incidence. Incidence of each disease was calculated for each assessment date by dividing the number of leaflets with at least one lesion by the total number of leaflets collected from each plot. In the case where disease incidence reached $\geq 1 \%$ between sampling dates, the latter sample date was used to mark time of disease onset. Disease severity was measured as the number of lesions per leaflet for each leaf spot disease separately and combined. These data were used to estimate the standardized area under the disease progress curve (stAUDPC) calculated as AUDPC divided by the duration of the epidemic (Campbell and Madden 1990). LLS predominance

Table 2. Number of cases (unique combinations of Peanut Rx risk factors) in Georgia and Florida for each location that were used in this study

\begin{tabular}{llr}
\hline Research sites & \multicolumn{1}{c}{ Location } & Frequency \\
\hline Attapulgus & Attapulgus, GA & 24 \\
Fire Tower & Tifton, GA & 22 \\
Ponder farm & Tifton, GA & 19 \\
Black Shank farm & Ty Ty, GA & 17 \\
RDC pivot & Tifton, GA & 13 \\
Marianna & Marianna, FL & 11 \\
Citra & Citra, FL & 8 \\
Lang farm & Tifton, GA & 8 \\
Plains & Plains, GA & 8 \\
Rigdon farm & Tifton, GA & 8 \\
ABAC farm & Tifton, GA & 4 \\
Quincy & Quincy, FL & 4 \\
Stripling & Camilla, GA & 8 \\
Sunbelt Expo & Moultrie, GA & 3 \\
Fish pond & Tifton, GA & 3 \\
Gibbs farm & Tifton, GA & 2 \\
Midville & Midville, GA & 2 \\
NESPAL field & Tifton, GA & 2 \\
Jones farm & Tifton, GA & 168 \\
Railroad field & Tifton, GA & \\
Total & & 1 \\
\hline a Rural Development Center. & & \\
b Abraham Baldwin Agricultural College. & \\
c National Environmentally Sound Production Agriculture Laboratory. & \\
& & 2
\end{tabular}


was estimated as the proportion of the total leaf spot epidemic attributed to LLS, and was calculated by dividing stAUDPC of LLS by the total stAUDPC (stAUDPC of ELS and LLS combined).

Statistical analyses. Mixed-effects linear regression was used to assess the relationship between Peanut Rx risk points and percent defoliation, LLS predominance. Risk points was considered a fixed effect and site-year was treated as a random effect. The analysis was implemented in R software (version 3.6.0; R Core Team 2019) where the function lmer() of package lme4 version 1.1-21 (Bates et al. 2015) was used to fit the mixed effects models, and the r2() function of package sjstats version 0.17.4 (Lüdecke 2019) was used to calculate the conditional coefficient of determination $\left(\mathrm{R}^{2}\right)$. In the sjstats package, the conditional $\mathrm{R}^{2}$, which describes the variance explained by both fixed and random factors, was calculated by following the methodology described by Nakagawa et al. (2017). A similar regression approach was used to determine the relationship between Peanut Rx risk points and the combined and separate epidemics of ELS and LLS, and included the following response variables: total stAUDPC, ELS stAUDPC, LLS stAUDPC, leaf spot onset, ELS onset, and LLS onset.

Mixed-effects multiple regression was used to evaluate the relationship between Peanut Rx factors and each disease variable. The potential Peanut Rx factors were cultivar risk, planting date (day of year), rotation $(0,1,2$, or $\geq 3$ years out of peanut), tillage (conventional $=0$; or reduced $=1$ ), field history (any leaf spot reported in previous years; yes $=1$ or no $=0$ ), and irrigation (yes $=1$ or no $=0$ ). Cultivar risk included risk points attributed to each cultivar. This was because a large number of cultivars shared the same risk points, and because many of the cultivars were included in only a few studies (see Table 3). Prior to fitting mixed-effects multiple regression models, a variable clustering procedure called PROC VARCLUS (Nelson 2001) was implemented using SAS version 9.4 (SAS Institute, Cary,

Table 3. Risk points and associated frequency for each Peanut Rx factor summarized across trials conducted from 2010 to 2016

\begin{tabular}{|c|c|c|c|}
\hline Risk factor & Risk category & Risk points & $N^{\mathrm{a}}$ \\
\hline \multirow[t]{4}{*}{ Cultivar $^{\mathrm{b}}$} & Susceptible & 30 & 33 \\
\hline & Moderately resistant & 25 & 2 \\
\hline & Resistant & 20 & 114 \\
\hline & Very resistant & 15 & 19 \\
\hline \multirow[t]{4}{*}{ Planting date } & $<$ May 1 & 0 & 13 \\
\hline & May $1-10$ & 5 & 18 \\
\hline & May $11-25$ & 10 & 86 \\
\hline & > May 25 & 15 & 51 \\
\hline \multirow[t]{4}{*}{ Rotation $^{\mathrm{c}}$} & 0 years & 25 & 42 \\
\hline & 1 year & 15 & 32 \\
\hline & 2 years & 10 & 19 \\
\hline & $>3$ years & 5 & 75 \\
\hline \multirow[t]{2}{*}{ Tillage } & Conventional & 10 & 160 \\
\hline & Reduced & 0 & 8 \\
\hline \multirow[t]{2}{*}{ Irrigation } & Yes & 10 & 149 \\
\hline & No & 0 & 19 \\
\hline \multirow[t]{2}{*}{ Field history ${ }^{\mathrm{d}}$} & Yes & 10 & 136 \\
\hline & No & 0 & 32 \\
\hline Historical leaf spot prevalence & Both $\mathrm{e}$ & $-^{f}$ & 39 \\
\hline \multirow{3}{*}{ (Potential new factor) } & ELS & - & 49 \\
\hline & LLS & - & 46 \\
\hline & Unknown & - & 34 \\
\hline
\end{tabular}

\footnotetext{
${ }^{a}$ Number of cases.
}

${ }^{b}$ Different categories under the cultivar risk factor represent resistance levels to both leaf spot diseases (early and late leaf spot of peanut).

${ }^{c}$ Number of years without peanut.

d 'Yes' was assigned to fields that had previously been used for fungicide studies that included untreated plots; 'No' was assigned to fields with a rotation $>3$ years, or for fields where diseases were heavily managed with fungicides in the previous seasons.

${ }^{\mathrm{e}}$ ELS = Early leaf spot; LLS = Late leaf spot; 'Both' signifies that both diseases were known to heavily contribute to the overall leaf spot epidemic in the previous peanut cropping season. 'Unknown' signifies that there was no record or knowledge of which disease was prevalent.

${ }^{\mathrm{f}}$ Since this is a new potential factor, no risk points are assigned.
NC). This procedure was implemented to identify and remove redundant Peanut Rx risk factors. The VARCLUS procedure assigns variables to different clusters based on high intracluster and low intercluster correlations. Only one variable in each cluster was retained for inclusion in subsequent regression analysis. For example, if a cluster had two risk factors, the one that had a better representation of its levels in the dataset was selected for regression analysis. Mixed effects regression was performed in $\mathrm{R}$ version 3.6.0 using packages lme 4 and sjstats as described in the previous paragraph. The selected Peanut Rx risk factors were considered as fixed effects, and site-year was treated as a random effect to account for variation due to different environments. Response variables included percent main stem defoliation, total AUDPC, leaf spot onset, ELS onset, LLS onset, ELS stAUDPC, LLS stAUDPC, and LLS predominance.

For each level of the new potential factor, historical leaf spot prevalence, onset time of ELS and LLS were compared using boxplots and two-sample $t$ tests. LLS predominance was tested using onesample $t$ test to determine whether it differed significantly from 0.5 . If it was not different from 0.5 , it would mean that the proportion of LLS and ELS in a given field is equal.

\section{Results}

After averaging across replicates, a total of 168 cases (unique combinations of levels of Peanut Rx risk factors) were obtained from field trials conducted in Georgia and Florida from 2010 to 2016. The frequency distribution of risk points showed that all the cases were in moderate and high risk categories (Fig. 1). There were 129 cases in the high risk category, with total points between 65 and 100, 39 cases in the moderate risk category, with total points between 40 and 64 points, and no low risk cases (10 to 39 points).

Summary statistics of each disease variable are displayed in Table 4. Percent defoliation ranged from 13.9 to 100, and stAUDPC ranged from 0 to 23.7 lesion-day (Table 4). Leaf spot onset ranged from 29 to 140 DAP; this value reflected the onset of ELS $90 \%$ of the time (data not shown). On average, ELS onset was approximately 20 days prior to that of LLS, and the earliest observations of ELS and LLS were at 29 and 50 DAP, respectively (Table 4). The average and maximum values of ELS stAUDPC were lower than those of LLS stAUDPC, and both diseases had cases with very low severity (values close to 0 ) (Table 4). The LLS predominance varied considerably between fields, with the maximum LLS predominance at almost one and the lowest at almost zero (Table 4).

Relationship of risk points to disease. Risk points had a significant positive effect on percent defoliation, total stAUDPC, and ELS stAUDPC, and a significant negative effect on LLS predominance, onset of ELS and LLS alone, and combined onset of ELS and LLS (Fig. 2 and Table 5). As expected, onset of the LLS was predicted

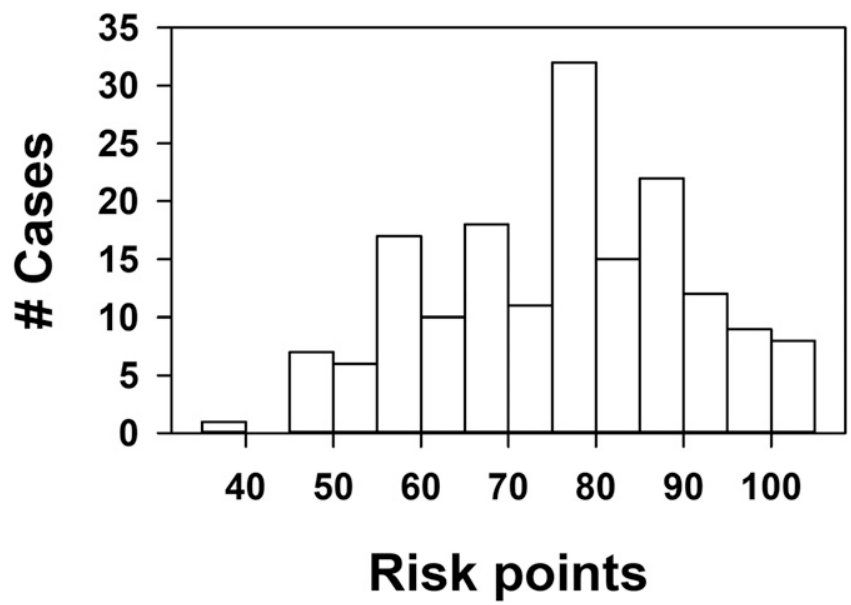

Fig. 1. Frequency distribution of total risk points calculated for each of the 168 unique combinations of Peanut Rx factors obtained from multiple field trials conducted in Georgia and Florida during 2010 to 2016. 
to be later in the season than onset of ELS (Fig. 2). The conditional $\mathrm{R}^{2}$ for disease onset were highest for combined leaf spot, followed by ELS alone, and then LLS alone (Table 5). For stAUDPC, the conditional $\mathrm{R}^{2}$ for ELS was a little bit higher than leaf spot combined, and no significant effect on LLS (Table 5). LLS predominance was affected negatively by risk points.

Evaluating Peanut Rx risk factors and disease. The six risk factors examined were grouped into four clusters based on the variable reduction technique. Rotation and tillage were in one cluster, and field history and irrigation were in another cluster. Other risk factors were in their own individual cluster. Between rotation and tillage, rotation was selected for inclusion in mixed effects regression analysis; and field history was chosen from the cluster that contained field history and irrigation (Table 6). Rotation and field history were chosen, because levels of these risk factors had better representation in the dataset than tillage and irrigation (Table 3).

Results from the mixed-effects multiple regression using Peanut $\mathrm{Rx}$ risk factors were similar to the risk points analyses, with risk factors having a higher conditional $\mathrm{R}^{2}$ value for explaining onset variables and LLS predominance than other disease variables. After accounting for randomness of site-years, the risk factors explained less variation for stAUDPC values than LLS predominance, percent defoliation, and onset variables (Table 7).

Rotation was a significant predictor of five out of eight response variables, and was the only factor that significantly affected LLS predominance (Table 7). Field history was similarly important for leaf spot, and ELS onset, Total stAUDPC, ELS stAUDPC, and percent defoliation. Cultivar was a significant predictor in six of the eight models (Table 7). Planting date was significant for four of the response variables (Table 7).

Onset of LLS coincided with onset of ELS in fields that had a prior history of LLS or fields that had no information on leaf spot prevalence. The onset of ELS was significantly earlier than LLS in fields with a prior history of ELS or both diseases (Fig. 3). LLS predominance was primarily associated with the historical leaf spot prevalence of each leaf spot (Fig. 4). As such, ELS was predominant in fields with a prior history of ELS, and LLS was predominant in fields with a prior history of LLS; fields with a prior history of 'Both' had an equal level of both diseases (Fig. 4).

\section{Discussion}

The results demonstrate that associated risk points significantly affect certain components of leaf spot epidemics. They also provide strong mechanistic support for the prescription fungicide programs based upon Peanut Rx that allow fewer fungicide applications in fields with moderate to low levels of risk without compromising yield (Woodward et al. 2010, 2014).

Risk points were more strongly related to ELS than LLS, and more strongly related to onset of disease than stAUDPC, an estimate of disease severity. This makes some sense, since most of the risk factors in the Peanut Rx index affect initial inoculum loads rather than secondary inoculum production. Our study did not see improved relationships of risk to disease onset when the leaf spot diseases were separated than when considered together, but only about $10 \%$ of our plots began leaf spot epidemics with LLS, so this result may be a consequence of most fields having ELS, even when LLS is the dominant disease.

Table 4. Summary statistics for measurements of early leaf spot (caused by Passalora arachidicola) and late leaf spot (caused by Nothopassalora personata) development in non-fungicide-treated plots of peanut in multiple field trials conducted in Georgia and Florida from 2010 to 2016

\begin{tabular}{|c|c|c|c|c|c|c|}
\hline Response variable & $N$ & Mean & Median & Standard deviation & Minimum & Maximum \\
\hline Percent defoliation $^{a}$ & 167 & 78.6 & 89.7 & 24.6 & 13.9 & 100.0 \\
\hline Leaf spot onset ${ }^{\mathrm{b}}$ & 168 & 77.3 & 77.1 & 27.0 & 29.0 & 140.0 \\
\hline ELS onset $^{\mathrm{c}}$ & 168 & 79.3 & 80.0 & 28.5 & 29.0 & 142.3 \\
\hline LLS onset ${ }^{\mathrm{c}}$ & 167 & 100.9 & 101.3 & 20.0 & 49.8 & 143.0 \\
\hline Total stAUDPC ${ }^{\mathrm{d}}$ & 166 & 6.5 & 5.7 & 4.2 & 0.00 & 23.7 \\
\hline ELS stAUDPC & 166 & 2.3 & 2.0 & 2.1 & 0.00 & 9.1 \\
\hline LLS stAUDPC & 166 & 4.2 & 2.8 & 4.4 & 0.00 & 23.1 \\
\hline LLS predominance ${ }^{f}$ & 166 & 0.55 & 0.61 & 0.35 & 0.01 & 0.99 \\
\hline
\end{tabular}

${ }^{a}$ Main stem defoliation assessed at the end of the season (generally 140 DAP, although some plots reached $100 \%$ defoliation prior to 140 DAP).

${ }^{\mathrm{b}}$ Days after planting to reach $1 \%$ lesion incidence regardless of ELS or LLS.

c Time in DAP when either leaf spot reached $1 \%$ lesion incidence.

${ }^{\mathrm{d}}$ Combined standardized AUDPC (units are lesion-day/leaf) of early and late leaf spot lesions per leaf.

e Standardized AUDPC of early (ELS) or late (LLS) leaf spot lesions per leaf.

${ }^{\mathrm{f}}$ LLS predominance (proportion of the total leaf spot epidemic attributed to late leaf spot; calculated by dividing the standardized AUDPC of late leaf spot by the total standardized AUDPC of early and late leaf spot combined).
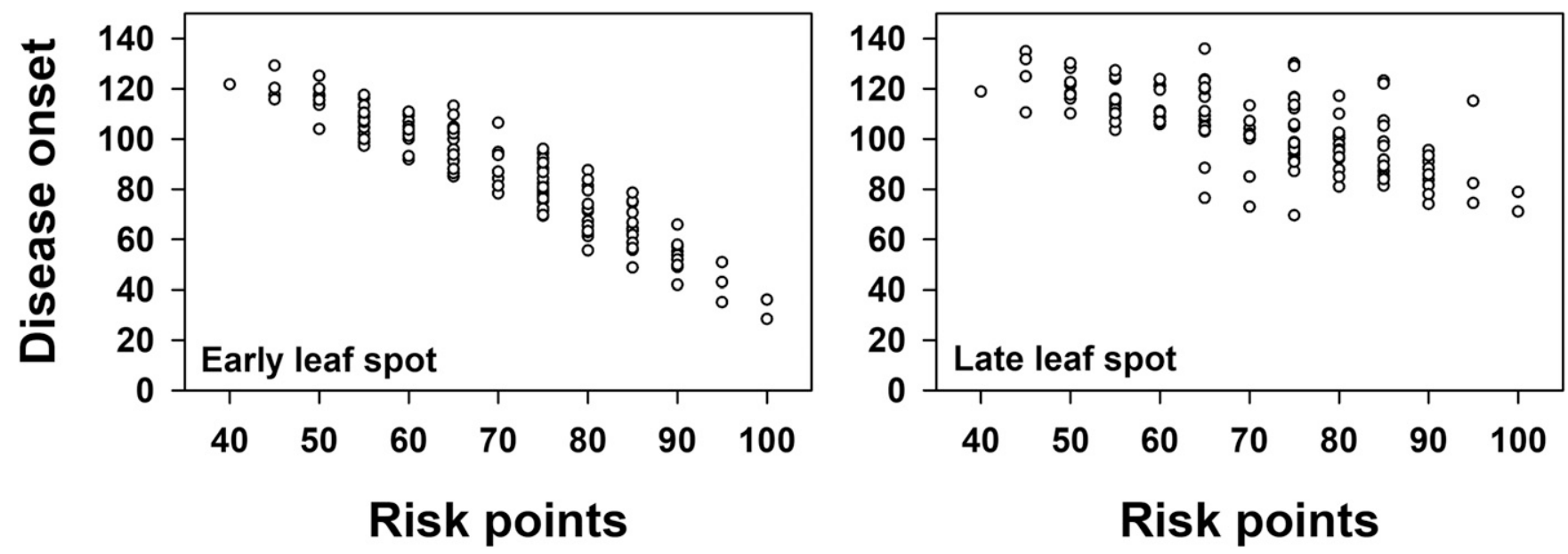

Fig. 2. Scatter plots showing predicted onset of early leaf spot (caused by Passalora arachidicola) and late leaf spot (caused by Nothopassalora personata) based on Peanut Rx risk points. 
The results from this study suggest that the current Peanut Rx threshold for risk categories may over-estimate risk. Based on the current threshold levels, all of the fields were categorized as highrisk or moderate-risk. There were no low-risk cases, and yet the onset of disease was $\geq 90$ DAP in fields with the lowest risk points and $\leq 40$ DAP in fields with the highest risk points. This discovery calls into question the recommended timing of the first fungicide application in the current Peanut Rx-based prescription fungicide programs. Currently, initial applications for high, moderate, and low risk prescription fungicide programs are recommended at 30, 37, and 44 DAP, respectively (Kemerait et al. 2017), yet actual disease onset was much more delayed in many moderate risk fields. It should be noted that, in the present study, ELS and LLS lesions were differentiated based on signs and symptoms which required detection of a sporulating lesion, and thus does not consider the time required for infection prior to the development of symptoms and signs. Both ELS and LLS have incubation periods of $\sim 7$ to 14 and latent periods of $\sim 14$ to 21 days, depending on genotype and environment (Cantonwine et al. 2008; Shew et al. 1988). Thus, the infection process for detection of either disease at 100 DAP would have commenced by $\sim 75$ to 80 DAP. Therefore, even when considering the time required for the infection process, these results suggest that current fungicide timings for Peanut Rx-based prescription fungicide programs could be adjusted to better match expected disease onset. To emphasize the point, we recently showed that in fields where the onset of disease is $>100$ DAP, four fungicide applications with the first fungicide application delayed up to 65 and 86 DAP still provided excellent leaf spot control (Fulmer 2017). Therefore, it may be that the data obtained from these studies can be used to reevaluate the thresholds for low-, moderate-, and high-risk groups.

Percent defoliation had a relatively stronger relationship with risk points than total stAUDPC, but neither was as strong as leaf spot onset. The final assessments of defoliation and lesion counts were made between $\sim 135$ and 145 DAP, and therefore was not uniform across all cases. More importantly, fields that were completely defoliated by 120 or 140 days could not be distinguished based on our final percent defoliation assessed between $\sim 135$ and 145 DAP, which was the case in a number of high risk scenarios (data not shown). Similarly, stAUDPC based on the number of lesions per leaflet may not have fully captured the disease severity since nondefoliated plants often have very high lesion numbers ( $>40$ for ELS and $>100$ for LLS) toward the end of the season (data not shown). Therefore, plants that experienced heavy defoliation at an early DAP may have reduced the number of possible lesions per leaflet (carrying capacity).

Results of the mixed-effects multiple regression analyses confirmed that all selected Peanut Rx risk factors contribute to the variability of at least one component of the combined and separate epidemic of ELS and LLS. However, not all factors affected ELS and LLS equally. We have recently documented that inoculum level, planting date, and cultivar affect both diseases, but the magnitude of the effect often differs between the two diseases as described below (Fulmer 2017).

The primary cultivar used in these studies was 'Georgia-06G', but the mixed-effects multiple regression approach still indicated that cultivar was a significant risk factor. We previously documented that the onset of LLS is later and the LLS stAUDPC is lower on 'Georgia-06G' compared with more susceptible cultivars such as 'Florunner' and 'Georgia Valencia' (Fulmer 2017). These data support previous reports that indicate that individual genotypes may differ in the level of resistance to each leaf spot pathogen (Abdou et al. 1974; Walls et al. 1985).

Planting date had a highly significant effect on defoliation and leaf spot onset, but not on stAUDPC values. A number of previous

Table 6. Summary of variable reduction technique to identify redundant Peanut Rx risk factors for use in prediction of severity and onset of early leaf spot (caused by Passalora arachidicola) and late leaf spot (caused by Nothopassalora personata) of peanut using data collected from non-fungicide-treated plots in Georgia and Florida from 2010 to 2016

\begin{tabular}{|c|c|c|c|}
\hline \multirow[b]{2}{*}{ Cluster } & \multirow[b]{2}{*}{ Variable } & \multicolumn{2}{|c|}{$\mathbf{R}^{2}$ with } \\
\hline & & Own cluster & Next cluster \\
\hline \multirow[t]{2}{*}{ Cluster 1} & Rotation $^{\mathrm{a}}$ & 0.66 & 0.050 \\
\hline & Tillage & 0.66 & 0.007 \\
\hline \multirow[t]{2}{*}{ Cluster 2} & Field history ${ }^{b}$ & 0.70 & 0.072 \\
\hline & Irrigation & 0.70 & 0.058 \\
\hline Cluster 3 & Cultivar & 1.00 & 0.006 \\
\hline Cluster 4 & Planting date & 1.00 & 0.032 \\
\hline
\end{tabular}

${ }^{a}$ Number of years without peanut.

$\mathrm{b}$ This variable indicates the presence of either leaf spot in the previous years.

Table 5. Results of mixed effects regression analysis conducted to explain variation in multiple response variables related to the general and specific epidemics of early and late leaf spot based on Peanut Rx risk points using data collected from non-fungicide-treated plots in Georgia and Florida from 2010 to 2016

\begin{tabular}{|c|c|c|c|c|c|c|}
\hline Response variable & Conditional $\mathbf{R}^{2}$ a & Predictor variable & Estimate & Standard error & $t$ Value & $P>|\mathbf{t}|$ \\
\hline \multirow[t]{2}{*}{ Percent defoliation ${ }^{\mathrm{b}}$} & 0.56 & Intercept & -0.007 & 9.08 & -0.001 & 0.999 \\
\hline & & Risk points & 1.06 & 0.126 & 8.41 & $<0.0001$ \\
\hline \multirow[t]{2}{*}{ Leaf spot onset ${ }^{\mathrm{c}}$} & 0.75 & Intercept & 178.3 & 7.08 & 25.2 & $<0.0001$ \\
\hline & & Risk points & -1.33 & 0.098 & -13.6 & $<0.0001$ \\
\hline \multirow[t]{2}{*}{ 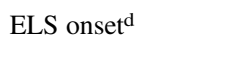 } & 0.74 & Intercept & 182.3 & 7.61 & 24.0 & $<0.0001$ \\
\hline & & Risk points & -1.35 & 0.106 & -12.8 & $<0.0001$ \\
\hline \multirow[t]{2}{*}{ LLS onset $^{\mathrm{d}}$} & 0.70 & Intercept & 153.2 & 7.06 & 21.7 & $<0.0001$ \\
\hline & & Risk points & -0.691 & 0.098 & -7.07 & $<0.0001$ \\
\hline \multirow[t]{2}{*}{ Total stAUDPC } & 0.49 & Intercept & -1.35 & 1.88 & -0.720 & 0.473 \\
\hline & & Risk points & 0.106 & 0.026 & 4.06 & $<0.0001$ \\
\hline \multirow[t]{2}{*}{ ELS stAUDPC } & 0.53 & Intercept & -3.64 & 0.812 & -4.48 & $<0.0001$ \\
\hline & & Risk points & 0.080 & 0.011 & 7.07 & $<0.0001$ \\
\hline \multirow[t]{2}{*}{ LLS stAUDPC } & 0.50 & Intercept & 2.07 & 2.04 & 1.01 & 0.312 \\
\hline & & Risk points & 0.030 & 0.028 & 1.05 & 0.295 \\
\hline \multirow[t]{2}{*}{ LLS predominance ${ }^{\mathrm{g}}$} & 0.70 & Intercept & 1.24 & 0.137 & 9.07 & $<0.0001$ \\
\hline & & Risk points & -0.009 & 0.002 & -4.92 & $<0.0001$ \\
\hline
\end{tabular}

\footnotetext{
${ }^{a}$ Conditional coefficient of determination $\left(\mathrm{R}^{2}\right)$ is calculated by using the methodology described by Nakagawa et al. (2017). It describes the variance explained by both fixed and random factors.

${ }^{\mathrm{b}}$ Main stem defoliation assessed at the end of the season (generally 140 DAP, although some plots reached 100\% defoliation prior to 140 DAP).

c Days after planting to reach $1 \%$ lesion incidence regardless of ELS or LLS.

d Time in DAP when either leaf spot reached $1 \%$ lesion incidence.

${ }^{\mathrm{e}}$ Combined standardized AUDPC of early and late leaf spot lesions per leaf.

${ }^{\mathrm{f}}$ Standardized AUDPC of early (ELS) or late (LLS) leaf spot lesions per leaf.

${ }^{\mathrm{g}}$ LLS predominance (proportion of the total leaf spot epidemic attributed to late leaf spot; calculated by dividing the standardized AUDPC of late leaf spot by the total standardized AUDPC of early and late leaf spot combined).
} 
studies documented that the onset of both leaf spots generally decreases with later planting dates (Jordan and Culbreath 2016; Shokes et al. 1982), but the magnitude of the response tends to be greater for LLS (Fulmer 2017). However, stAUDPC values were not affected by planting date in the present study. This may be partly attributed to the confounding factor of defoliation, as previously described above.

Rotation consistently had a significant effect on leaf spot development across response variables, which corroborates results of previous studies. In a previous study, a 1-year rotation away from peanut significantly reduced LLS severity (Kucharek 1975). Brenneman et al. (1995) found that leaf spot severity decreased when peanuts were rotated to bahiagrass for $0,1,2$, or 3 years. Currently, apart from cultivar, the Peanut Rx weighting system places the greatest weight on rotation (Kemerait et al. 2017), and the results from these studies validate this emphasis. Interestingly, we found that LLS tended to be most prevalent in a majority of the fields with the longest rotations away from peanut. This could be due to differences in the survival or dispersal of the two pathogens. However, further research is needed to substantiate this hypothesis.

Tillage was not included in the mixed-effects multiple regression analysis, because there were very few cases with reduced tillage. However, the effect of reduced or strip tillage to delay the epidemics of ELS has previously been well documented (Cantonwine et al. 2007; Monfort et al. 2004). Cantonwine et al. (2007) suggested that because ELS was the predominant disease in their studies, further work would be needed to determine the effect of tillage on LLS development. We suggest that this statement still applies, and that further work is needed to determine the interactive effects of rotation and tillage for each leaf spot.

Leaf spot epidemics are dependent upon moisture, and this has been the rationale behind research aimed at developing weather-based advisories for peanut growers (Jacobi et al. 1995; Jensen and Boyle 1965, 1966; Phipps et al. 1997). Peanut Rx is unique in

Table 7. Results of mixed effects regression analysis conducted to explain variation in multiple response variables related to the general and specific epidemics of early and late leaf spot based on selected Peanut Rx risk factors using data collected from non-fungicide-treated plots in Georgia and Florida from 2010 to 2016

\begin{tabular}{|c|c|c|c|c|c|c|}
\hline Response variable & $\mathbf{R}^{2} \mathbf{a}$ & Predictor variable & Estimate & Standard error & $t$ value & $P>|t|$ \\
\hline \multirow[t]{5}{*}{ Percent defoliation $^{\mathrm{b}}$} & 0.64 & Intercept & 37.2 & 15.8 & 2.36 & 0.0197 \\
\hline & & Planting date & 0.397 & 0.098 & 4.05 & 0.0001 \\
\hline & & Rotation & -9.03 & 1.39 & -6.49 & $<0.0001$ \\
\hline & & Cultivar & -0.78 & 0.301 & -2.60 & 0.0105 \\
\hline & & Field history & 15.2 & 4.30 & 3.53 & 0.0006 \\
\hline \multirow[t]{5}{*}{ Leaf spot onset ${ }^{c}$} & 0.77 & Intercept & 144.3 & 12.6 & 11.5 & $<0.0001$ \\
\hline & & Planting date & -0.383 & 0.078 & -4.91 & $<0.0001$ \\
\hline & & Rotation & 11.0 & 1.11 & 9.92 & $<0.0001$ \\
\hline & & Cultivar & -0.470 & 0.238 & -1.98 & 0.0499 \\
\hline & & Field history & -17.4 & 3.40 & -5.14 & $<0.0001$ \\
\hline \multirow[t]{5}{*}{ ELS onset ${ }^{d}$} & 0.77 & Intercept & 142.0 & 13.4 & 10.6 & $<0.0001$ \\
\hline & & Planting date & -0.367 & 0.083 & -4.42 & $<0.0001$ \\
\hline & & Rotation & 11.8 & 1.19 & 9.96 & $<0.0001$ \\
\hline & & Cultivar & -0.453 & 0.253 & -1.79 & 0.0755 \\
\hline & & Field history & -16.0 & 3.64 & -4.41 & $<0.0001$ \\
\hline \multirow[t]{5}{*}{ 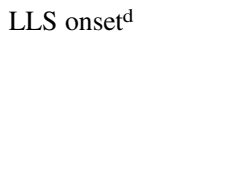 } & 0.81 & Intercept & 209.3 & 9.82 & 21.3 & $<0.0001$ \\
\hline & & Planting date & -0.605 & 0.061 & -10.0 & $<0.0001$ \\
\hline & & Rotation & 1.31 & 0.998 & 1.31 & 0.1925 \\
\hline & & Cultivar & -0.816 & 0.176 & -4.64 & $<0.0001$ \\
\hline & & Field history & -5.73 & 3.10 & -1.85 & 0.0659 \\
\hline \multirow[t]{5}{*}{ Total stAUDPC } & 0.50 & Intercept & 0.730 & 3.38 & 0.216 & 0.8291 \\
\hline & & Planting date & 0.002 & 0.021 & 0.117 & 0.9068 \\
\hline & & Rotation & -0.217 & 0.310 & -0.699 & 0.4855 \\
\hline & & Cultivar & 0.189 & 0.063 & 3.00 & 0.0032 \\
\hline & & Field history & 1.89 & 0.935 & 2.02 & 0.0450 \\
\hline \multirow[t]{5}{*}{ ELS stAUDPC ${ }^{\mathrm{f}}$} & 0.58 & Intercept & 3.19 & 1.44 & 2.21 & 0.0287 \\
\hline & & Planting date & -0.013 & 0.009 & -1.47 & 0.1449 \\
\hline & & Rotation & -0.838 & 0.127 & -6.58 & $<0.0001$ \\
\hline & & Cultivar & 0.060 & 0.027 & 2.20 & 0.0297 \\
\hline & & Field history & 0.863 & 0.382 & 2.26 & 0.0255 \\
\hline \multirow{5}{*}{ LLS stAUDPC ${ }^{\mathrm{f}}$} & 0.52 & Intercept & -2.63 & 3.49 & -0.754 & 0.4522 \\
\hline & & Planting date & 0.017 & 0.022 & 0.794 & 0.4282 \\
\hline & & Rotation & 0.597 & 0.327 & 1.83 & 0.0699 \\
\hline & & Cultivar & 0.132 & 0.065 & 2.04 & 0.0434 \\
\hline & & Field history & 0.926 & 0.988 & 0.937 & 0.3506 \\
\hline \multirow[t]{5}{*}{ LLS predominanceg } & 0.79 & Intercept & 0.233 & 0.198 & 1.18 & 0.2412 \\
\hline & & Planting date & 0.001 & 0.001 & 0.625 & 0.5330 \\
\hline & & Rotation & 0.164 & 0.019 & 8.50 & $<0.0001$ \\
\hline & & Cultivar & 0.001 & 0.004 & 0.224 & 0.8229 \\
\hline & & Field history & -0.027 & 0.061 & -0.438 & 0.6618 \\
\hline
\end{tabular}

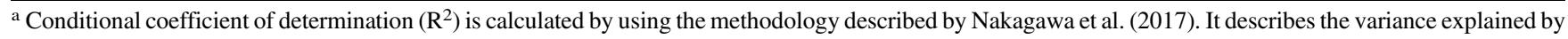
both fixed and random factors.

${ }^{\mathrm{b}}$ Main stem defoliation assessed at the end of the season (generally 140 DAP, although some plots reached 100\% defoliation prior to 140 DAP).

${ }^{\mathrm{c}}$ Days after planting to reach $1 \%$ lesion incidence regardless of ELS or LLS.

${ }^{\mathrm{d}}$ Time in DAP when either leaf spot reached $1 \%$ lesion incidence.

e Combined standardized AUDPC of early and late leaf spot lesions per leaf.

${ }^{\mathrm{f}}$ Standardized AUDPC of early or late leaf spot lesions per leaf.

${ }^{g}$ LLS predominance (proportion of the total leaf spot epidemic attributed to late leaf spot; calculated by dividing the standardized AUDPC of late leaf spot by the total standardized AUDPC of early and late leaf spot combined).
} 
that there is no major weather component included other than irrigation. Peanut Rx gives up some predictive potential at the expense of providing a less time-demanding tool for growers. However, our results indicate that Peanut Rx risk points provide prediction of disease onset regardless of variations in the weather patterns across years. It should be noted that most $(88 \%)$ of the fields in these studies were irrigated, which likely provided a more uniformly moist environment. Therefore, Peanut Rx may be most applicable under irrigated conditions typical in the southeastern production region of the United States. Prediction of leaf spot onset based on Peanut Rx in a dryland situation may result in an over prediction of risk, in which case,

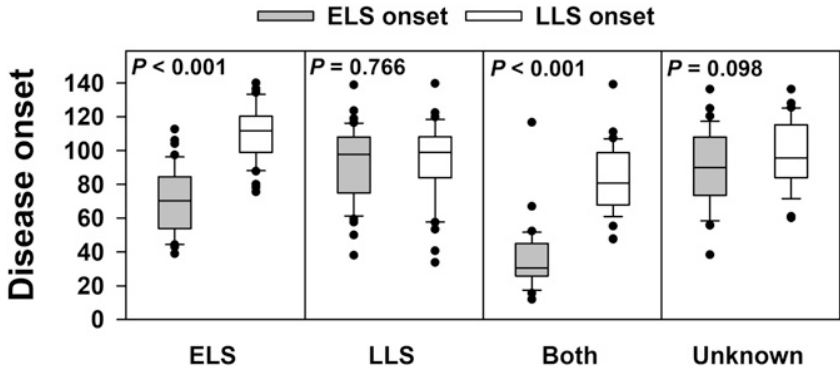

Historical leaf spot prevalance

Fig. 3. Distribution of early leaf spot (ELS) and late leaf spot (LLS) onset in relation to the historical leaf spot prevalence. ELS and LLS signify that fields had previously been documented to have a history of being predominantly ELS or LLS, respectively. 'Both' signifies that both diseases were known to contribute heavily to the epidemic in the previous peanut cropping season. 'Unknown' signifies that there was no record or knowledge of which disease was prevalent, which was generally associated with fields that had been out of peanut for $>5$ years. For ELS, $n=49$; LLS, $n=46$; Both, $n=39$; Unknown, $n=34$. Data were collected from non-fungicide-treated plots in Georgia and Florida from 2010 to 2016. $P$ value indicates the significance of $t$ test that was conducted to compare ELS and LLS onset within each historical leaf spot prevalence class. Early and late leaf spot of peanut are caused by Passalora arachidicola and Nothopassalora personata, respectively.

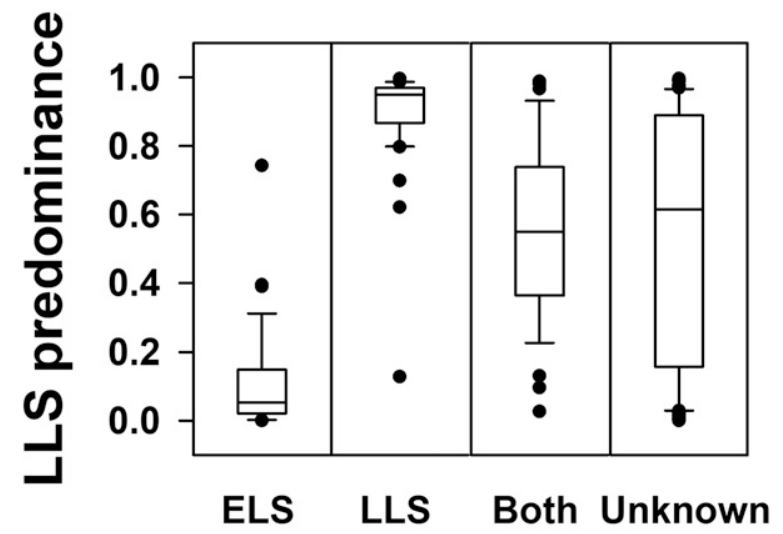

\section{Historical leaf spot prevalance}

Fig. 4. Distribution of LLS (late leaf spot) predominance (proportion of the stAUDPC attributed to late leaf spot) in relation to historical leaf spot prevalence; stAUDPC stands for standardized area under the disease progress curve. ELS (early leaf spot) and LLS signify that fields had previously been documented to have a history of being predominantly ELS or LLS, respectively. 'Both' signifies that both diseases were known to contribute heavily to the epidemic in the previous peanut cropping season. 'Unknown' signifies that there was no record or knowledge of which disease was prevalent, and was generally associated with fields that had been out of peanut for $>5$ years. For ELS, $n=49$; LLS, $n=46$; Both, $n=39$; Unknown, $n=$ 34. Data were collected from non-fungicide-treated plots in Georgia and Florida from 2010 to 2016. One sample $t$ test results for null hypothesis 'LLS predominance $=0.5^{\prime}$ are as follows: ELS $(P<0.001)$, LLS $(P<0.001)$, Both $(P=$ $0.209)$, and Unknown $(P<0.001)$. Early and late leaf spot of peanut are caused by Passalora arachidicola and Nothopassalora personata, respectively. growers would follow a fungicide application schedule as they would in the absence of Peanut Rx.

Field history is one of the most challenging Peanut Rx risk factors to quantify because of the subjective nature of the characterization, and as a result, each grower may interpret this differently. The purpose of including this factor is to help provide an indirect estimate of the inoculum potential of each field (along with rotation) by assessing whether a disease outbreak had occurred in the field in recent history. Presumably, a well-managed field would result in very little to no inoculum carryover. In these studies, we attempted to standardize the qualification by assigning 'Yes' to fields that had previously been used for fungicide studies that included non-fungicidetreated plots; 'No' was assigned to fields with a rotation $>3$ years, or for fields where diseases were heavily managed with fungicides in the previous seasons. Under this classification system, we found that field history did account for some of the variability in the onset of both diseases. However, these results may reflect the effect of rotation more than of field history. While more research on the interaction of these factors may be warranted, the conclusion based on our combined experience is that field history is worthwhile to include in the Peanut Rx risk index as an additional safety factor.

Smith and Littrell (1980) suggested that a number of factors, including initial inoculum source, cultivar, and fungicide, may influence the shift from ELS to LLS. We recently reported that while planting date and cultivar can affect the predominance of each leaf spot disease, initial inoculum source appears to have the most significant impact (Fulmer 2017). In this study, we report that knowledge of historical leaf spot prevalence proved to be a consistent indicator of future predominance in a given field. This helps to confirm the hypothesis of Smith and Littrell (1980) as well as further validate commonly held beliefs. From a practical standpoint, we suggest that it may be possible to use the knowledge of historical leaf spot prevalence as part of an integrated management system by selecting a cultivar with more resistance to the predominant leaf spot. Additionally, we suggest that, based on the differences in ELS and LLS onset, the ability to predict which disease will predominate could be another factor used to adjust initial fungicide timings.

In conclusion, the results presented here demonstrate that Peanut Rx is a very effective tool for predicting leaf spot onset-regardless of which leaf spot is predominant. These data support previous studies that documented the individual contribution of each risk factor and confirm that a high level of predictive accuracy can be obtained without knowledge of in-season weather conditions. Furthermore, because of a significant relationship between disease onset and total leaf spot risk points, and resulting unequal distribution of risk groups, these data suggest that the current thresholds for differentiating high, moderate, and low risk fields may need to be modified. We also report that the knowledge of historical leaf spot prevalence could be a potential predictor of which disease will be predominant, and we hypothesize that this knowledge may be useful for refining our ability to manage each disease with reduced fungicide input programs.

\section{Acknowledgments}

We thank the following personnel at the University of Georgia for all of the technical assistance provided: Stan Jones, Billy Mills, Lee Hitson, John Paulk, Andy Carter, Dewayne Dales, Mike Heath, Eric Smith, Hunt Sanders, Dan Everts, Cliff Riner, Randy Hill, Denny Thigpin, Anthony Black, Calvin Perry, Bobby Washington, Caleb Clements, Jarod Walls, Lina Flor Young, Jeannette Mixon, Jhen Bennett, and Edna Shannon. We also thank the following personnel at the University of Florida for all of the technical assistance provided: Mark Gomillion, Jim Boyer, and Maynard Douglas.

\section{Literature Cited}

Abdou, Y. A.-M., Gregory, W. C., and Cooper, W. E. 1974. Sources and nature of resistance to Cercospora arachidicola Hori and Cercosporidium personatum (Beck \& Curtis) Deighton in Arachis species. Peanut Sci. 1:6-11.

Backman, P., and Crawford, M. 1984. Relationship between yield loss and severity of early and late leafspot diseases of peanut. Phytopathology 74:1101-1103.

Bates, D., Maechler, M., Bolker, B., and Walker, S. 2015. Fitting Linear MixedEffects Models Using lme4. J. Stat. Softw. 67:1-48.

Beasley, J. P., Jr., ed. 2010. 2010 Peanut Update. Coop. Ext. Ser. College of Agric. Environ. Sci., University of Georgia, Athens. 
Brenneman, T., Sumner, D., Baird, R., Burton, G., and Minton, N. 1995. Suppression of foliar and soilborne peanut diseases in bahiagrass rotations. Phytopathology 85:948-952.

Campbell, C. L., and Madden, L. V. 1990. Introduction to Plant Disease Epidemiology. John Wiley \& Sons, New York, NY.

Cantonwine, E., Culbreath, A., Holbrook, C., and Gorbet, D. 2008. Disease progress of early leaf spot and components of resistance to Cercospora arachidicola and Cercosporidium personatum in runner-type peanut cultivars. Peanut Sci. 35:1-10.

Cantonwine, E., Culbreath, A., and Stevenson, K. 2007. Characterization of early leaf spot suppression by strip tillage in peanut. Phytopathology 97:187-194.

Culbreath, A., Kemerait, R., Jr., and Brenneman, T. 2006. Management of early leaf spot of peanut as affected by fungicide and date of spray program initiation. Online. Plant Health Prog. 7:1.

Damicone, J., Jackson, K., Sholar, J., and Gregory, M. 1994. Evaluation of a weather-based spray advisory for management of early leaf spot of peanut in Oklahoma. Peanut Sci. 21:115-121.

Davis, D., Jacobi, J., and Backman, P. 1993. Twenty-four-hour rainfall, a simple environmental variable for predicting peanut leaf spot epidemics. Plant Dis. 77:722-725.

Fulmer, A. M. 2017. Differentiation, prediction and management of early and late leaf spot of peanut in the southeastern United States and Haiti. Ph.D. Diss. University of Georgia, Athens.

Hemingway, J. 1955. The prevalence of two species of Cercospora on groundnuts. Trans. Br. Mycol. Soc. 38:243-246.

Jackson, L. 1981. Distribution and severity of peanut leafspot in Florida. Phytopathology 71:324-328.

Jacobi, J., Backman, P., Davis, D., and Brannen, P. 1995. AU-Pnuts advisory I: Development of a rule-based system for scheduling peanut leaf spot fungicide applications. Plant Dis. 79:666-671.

Jenkins, W. A. 1938. Two fungi causing leaf spot of peanut. J. Agric. Res. 56:317-332.

Jensen, R., and Boyle, L. 1965. The effect of temperature, relative humidity and precipitation on peanut leafspot. Plant Dis. Rep. 49:975-978.

Jensen, R. E., and Boyle, L. W. 1966. A technique for forecasting leafspot on peanuts. Plant Dis. Rep. 50:810-814.

Jordan, B., and Culbreath, A. 2016. Effect of planting date and peanut cultivar on leaf spot epidemics and pod yield with implications for organic production. (Abstr.) Phytopathology 106:S2.6.

Kemerait, R. C., Jr. 2013. Georgia Plant Disease Loss Estimates. Coop. Ext. Ser. Bull. 102-6, University of Georgia, Athens.

Kemerait, R. C., Jr. 2014. Georgia Plant Disease Loss Estimates. Coop. Ext. Ser. Bull. 102-7, University of Georgia, Athens.

Kemerait, R. C., Jr. 2015. Georgia Plant Disease Loss Estimates. Coop. Ext. Ser. Bull. 102-7, University of Georgia, Athens.

Kemerait, R. C., Brenneman, T. B., and Culbreath, A. K. 2004. A risk index for leaf spot and soilborne diseases of peanut in Georgia. Pages 83-90 in: 2003 Georgia Peanut Research and Extension Report. T. B. Brenneman and C. L. Butts, eds. Univ. of Ga. Coop. Ext. Ser. and U.S. Dep. Agric.

Kemerait, R. C., Jr., Brenneman, T. B., and Culbreath, A. K. 2017. Peanut disease update. Pages 23-62 in: 2017 Peanut Update. W. Monfort, ed. Coop. Ext. Ser. College of Agric. Environ. Sci. University of Georgia, Athens.

Kucharek, T. 1975. Reduction of Cercospora leafspots of peanut with crop rotation. Plant Dis. Rep. 59:822-823.

Lüdecke, D. 2019. sjstats: Statistical Functions for Regression Models (Version 0.17.4). URL: https://cran.r-project.org/web/packages/sjstats/index.html.
Miller, L. I. 1953. Studies of the parasitism of Cercospora arachidicola Hori and Cercospora personata (Berk. \& M.A. Curtis). Ph.D. Diss. University of Minnesota, Minneapolis, MN.

Monfort, W., Culbreath, A., Stevenson, K., Brenneman, T., Gorbet, D., and Phatak, S. 2004. Effects of reduced tillage, resistant cultivars, and reduced fungicide inputs on progress of early leaf spot of peanut (Arachis hypogaea). Plant Dis. 88:858-864.

Nakagawa, S., Johnson, P. C. D., and Schielzeth, H. 2017. The coefficient of determination $\mathrm{R}^{2}$ and intra-class correlation coefficient from generalized linear mixed-effects models revisited and expanded. J. R. Soc. Interface 14: 20170213.

Nelson, B. D. 2001. Variable reduction for modeling using PROC VARCLUS Paper No. 261-26 in: Proc. 26 Annu. SAS Users Group Int. Conf. SAS Institute Inc., Cary, NC., https://support.sas.com/resources/papers/proceedings/ proceedings/sugi26/p261-26.pdf

Parvin, D., Jr., Smith, D., and Crosby, F. 1974. Development and evaluation of a computerized forecasting method for Cercospora leafspot of peanuts. Phytopathology 64:385-388.

Phipps, P., and Powell, N. 1984. Evaluation of criteria for the utilization of peanut leafspot advisories in Virginia. Phytopathology 74:1189-1193.

Phipps, P. M., Deck, S. H., and Walker, D. R. 1997. Weather-based crop and disease advisories for peanuts in Virginia. Plant Dis. 81:236-244.

R Core Team. 2019. R: A language and environment for statistical computing. $\mathrm{R}$ Foundation for Statistical Computing, Vienna, Austria. URL https://www.Rproject.org/.

Shew, B., Beute, M., and Wynne, J. 1988. Effects of temperature and relative humidity on expression of resistance to Cercosporidium personatum in peanut. Phytopathology 78:493-498.

Shokes, F., and Culbreath, A. K. 1997. Early and late leaf spots. Pages 17-20 in: Compendium of Peanut Diseases, 2nd ed. N. Kokalis-Burelle, D. Porter, R. Rodriguez-Kabana, D. Smith, and P. Subrahmanyam, eds. American Phytopathological Society, St. Paul, MN.

Shokes, F., Gorbet, D., and Sanden, G. 1982. Effect of planting date and date of spray initiation on control of peanut leaf spots in Florida. Plant Dis. 66:574-575.

Smith, D. H., and Littrell, R. H. 1980. Management of peanut foliar diseases with fungicides. Plant Dis. 64:356-361.

Videira, S. I. R., Groenewald, J. Z., Nakashima, C., Braun, U., Barreto, R. W., de Wit, P. J. G. M., and Crous, P. W. 2017. Mycosphaerellaceae - Chaos or clarity? Stud. Mycol. 87:257-421.

Walls, S. B., Wynne, J., and Beute, M. 1985. Resistance to late leafspot peanut of progenies selected for resistance to early leafspot. Peanut Sci. 12:17-22.

Woodward, J., Brenneman, T., Kemerait, R., Culbreath, A., and Smith, N. 2010 Management of peanut diseases with reduced input fungicide programs in fields with varying levels of disease risk. Crop Prot. 29:222-229.

Woodward, J., Brenneman, T., Kemerait, R., Jr., Culbreath, A., and Smith, N. 2014. On-farm evaluations of reduced input fungicide programs in peanut fields with low, moderate, or high levels of disease risk. Peanut Sci. 41: 50-57.

Woodward, J. E. 2006. Optimizing efficacy and economic benefits of fungicides for peanut disease control via pre-plant analysis of disease risk and irrigation timing. Ph.D. diss. University of Georgia, Athens, GA.

Woodward, J. E., Brenneman, T. B., Kemerait, R. C., Smith, N. B., Culbreath A. K., and Stevenson, K. L. 2008. Use of resistant cultivars and reduced fungicide programs to manage peanut diseases in irrigated and nonirrigated fields. Plant Dis. 92:896-902. 